\title{
THE EFFECT OF BEVERAGES ON THE RELEASE OF CALCIUM FROM THE ENAMEL SURFACE
}

A.R. Fathilah, Z.H.A. Rahim. The effect of beverages on the release of calcium from the enamel surface. Annal Dent Univ Malaya 2008; 15(1): 1-4.

\begin{abstract}
In this study, the effect of beverages $($ CokeTM, Sprite $^{\mathrm{TM}}$, Ribena ${ }^{\mathrm{TM}}$, Chrysanthemum tea and mineral water) on the demineralisation of the enamel surface was investigated. Demineralisation was determined by the rate of calcium released from the enamel surface on exposure to the beverages. Calcium was determined using the EDTA titration method. The $\mathrm{pH}$ of these beverages was measured using a $\mathrm{pH}$ meter and found to be in the acidic range (2.43 to 5.79) while mineral water which served as a control has a $\mathrm{pH}$ of 7.00 . It was found that the rate of calcium released from $\operatorname{Coke}^{\mathrm{TM}}(0.76 \mu \mathrm{g} / \mathrm{min})$ showed a significant mean difference from Sprite ${ }^{\mathrm{TM}}$ $(0.38 \mu \mathrm{g} / \mathrm{min})$, Chrysanthemum tea $(0.10 \mu \mathrm{g} / \mathrm{min})$ and mineral water $(0.00 \mu \mathrm{g} / \mathrm{min})$ at $\mathrm{p}<.05$, but was however not significantly different from Ribena ${ }^{\mathrm{TM}}$. Likewise, Chrysanthemum tea and mineral water also showed statistically no significant mean difference in the released of calcium during the study period. The results obtained in this study indicated that beverages with low $\mathrm{pH}$ may pose detrimental effect on the enamel surface which could have clinical implication, especially in people with salivary gland dysfunction or low salivary flow.
\end{abstract}

Key words: critical $\mathrm{pH}$; demineralisation; solubility product; ionic product; enamel surface

\section{INTRODUCTION}

Enamel is the hardest tissue in the body and forms the outermost layer of the tooth. At the early phase of its formation, enamel is composed of both inorganic and organic components. However as it matures, there is a gradual influx of more minerals which are mainly calcium and phosphate in the form of hydroxyapatite (HA) crystals into the enamel matrix (1). A matured enamel will eventually have about $97 \%(\mathrm{w} / \mathrm{w})$ of its matrix mineralized, with approximately $3 \%$ water and less than $1 \%$ organic matrix.

As an inorganic tissue, the integrity of the enamel is very much under the influence of $\mathrm{pH}$ and the presence of minerals in the saliva. Critical $\mathrm{pH}$ is the $\mathrm{pH}$ at which a solution is just saturated with respect to a particular mineral such as the enamel $(2,3)$. At this $\mathrm{pH}$, the ionic product (Ip) of the
Original Article

A.R. Fathilah ${ }^{1}$, Z.H.A. Rahim ${ }^{1}$
${ }^{1}$ Department of Oral Biology
Faculty of Dentistry
University of Malaya
50603 Kuala Lumpur, Malaysia
Tel: +60-3-79677416
Fax: $+60-3-79674536$
Email: Eathilah@um.edu.m.
Email: zubaidar@um.edu.m.
Corresponding author: Dr Fathilah Abdul Razak

mineral is said to be equal to its solubility product $(K s p)$. In a situation where the $\mathrm{pH}$ of the solution is less than the critical $\mathrm{pH}(I p<K s p)$, the saliva is said to be unsaturated with respect to the mineral. Conversely, when the $\mathrm{pH}$ is above the critical $\mathrm{pH}$, the solution is supersaturated (I $p>K s p$ ) and in this situation, minerals will tend to precipitate out of the solution. It has been reported that the solubility of the enamel surface and its critical $\mathrm{pH}$ are not fixed but, vary slowly as the mineral solubility of enamel changes with repeated $\mathrm{pH}$ cycling $(2,3)$. In people with low salivary calcium and phosphates ratio, the critical pH may be 6.5 and in those with higher ratio, it is $5.5(2)$.

In the oral environment, the saliva and plaque fluid are supersaturated with calcium and phosphate with respect to the enamel. This explains why teeth do not dissolve into saliva or the plaque fluid $(2,4)$. However, transient fluctuations of $\mathrm{pH}$ of the oral ecosystem may be induced by the frequency and type of food taken and variations in the flow of saliva. Frequent and prolonged exposure to low $\mathrm{pH}$ may result in a more rapid demineralisation of the enamel surface $(2,5)$.

The aim of this in vitro study was to investigate the effect of beverages (Coke ${ }^{\mathrm{TM}}$, Sprite ${ }^{\mathrm{TM}}$, Ribena $^{\mathrm{TM}}$, Chrysanthemum tea and mineral water) on enamel surface demineralisation.

\section{MATERIALS AND METHODS}

\section{Selection of teeth used in the study}

Non-carious teeth (15 canines, 30 premolars and 15 molars) were selected and cleaned prior to use in the experiment. They were then divided into 3 sets of 5 groups of teeth, labeled as Group I $\left(\mathrm{Coke}^{\mathrm{TM}}\right)$, Group II (Sprite ${ }^{\mathrm{TM}}$ ) Group III (Ribena ${ }^{\mathrm{TM}}$ ), Group IV (Chrysanthemum tea) and Group V (Mineral 
water). Each group consisted of a canine, two premolars and a molar to allow for the standardization of the type of teeth used in the study.

\section{Preparation of tooth enamel surface}

For each tooth in the respective groups, three coats of nail varnish were applied to the whole surface area of the root (cemento-enamel junction to the apex) exposing only surfaces of the enamel. This was to prevent any release of calcium from the cementum.

\section{Measurement of the $\mathrm{pH}$ of beverages}

$10 \mathrm{ml}$ of $\mathrm{Coke}^{\mathrm{TM}}$, Sprite ${ }^{\mathrm{TM}}$, Ribena ${ }^{\mathrm{TM}}$, Chrysanthemum tea and mineral water was pipetted into separate clean beakers and then left at room temperature $\left(26-28{ }^{\circ} \mathrm{C}\right)$ for 10 minutes. The $\mathrm{pH}$ of the beverages was then measured using a $\mathrm{pH}$ meter (Hanna H1-8417 Instrument). Three $\mathrm{pH}$ readings were recorded for each beverage.

\section{Determination of the Rate of Calcium Released from Enamel Surface of the Teeth Immersed in Beverages}

The teeth in Group I were placed in a beaker containing $20 \mathrm{ml}$ of $\mathrm{Coke}^{\mathrm{TM}}$ and kept at room temperature $\left(26-28^{\circ} \mathrm{C}\right)$. At every $15 \mathrm{~min}$ intervals, $0.2 \mathrm{ml}$ of Coke was pipetted out and used for the determination of calcium. The experiment was carried out over a period of 2 hours. The experiment was repeated for Group II, III, IV and V. The rate of calcium released during the 2 hours exposure to the respective beverages was analysed and compared.

\section{Determination of calcium}

Calcium was determined using the titration method. At every 15 minutes intervals, $0.2 \mathrm{ml}$ of the beverage was pipetted out and put into a conical flask containing calcon, which is a dye used in the experiment to indicate the end point of the titration. The content was then titrated with EDTA from a microbiuret. The volume of EDTA used to produce the end point was recorded. Determination at each time intervals was carried out in triplicates.

\section{Statistical analysis}

Statistical analysis was carried out using SPSS one way analysis of variance (ANOVA). Results were expressed as mean \pm standard deviation from nine determination $(n=9)$ and a significant level of $p<.05$.

\section{RESULTS}

\section{$\mathrm{pH}$ of the beverages}

Table 1 shows the $\mathrm{pH}$ of the respective beverages. Coke $^{\mathrm{TM}}$ with a $\mathrm{pH}$ of 2.43 was the most acidic amongst the beverages. Sprite ${ }^{\mathrm{TM}}$ and Ribena ${ }^{\mathrm{TM}}$ have $\mathrm{pH}$ values of 3.31 and 3.02 , respectively. While the
$\mathrm{pH}$ of mineral water was recorded at about neutral, the $\mathrm{pH}$ of chrysanthemum tea was slightly acidic at 5.79 .

\section{The Rate of Calcium Released from Enamel Surface of Teeth Immersed in Beverages}

Figure 1 showed the profiles of calcium released from the enamel surface following exposure to the 5 types of beverages. The highest rate of calcium released was exhibited by Coke ${ }^{\mathrm{TM}}$ at $0.76 \pm 0.00 \mathrm{mg} /$ $\mathrm{ml}$. This was followed in descending order by Ribena $^{\mathrm{TM}}$, Sprite ${ }^{\mathrm{TM}}$ and Chrysanthemum tea at 0.67 $\pm 0.00 \mathrm{mg} / \mathrm{ml}, 0.38 \pm 0.00 \mathrm{mg} / \mathrm{ml}$ and $0.10 \pm 0.00$ $\mathrm{mg} / \mathrm{ml}$, respectively. Mineral water did not display any release of calcium over the study period. It was also observed in Figure 1 that the rate of calcium released from Coke ${ }^{\mathrm{TM}}$ showed a significant mean difference from Sprite ${ }^{\mathrm{TM}}$, Chrysanthemum tea and mineral water at $p<.05$ but was however not significantly different from Ribena ${ }^{\mathrm{TM}}$. Similar observation was made between Chrysanthemum tea and mineral water which statistically showed no significant mean difference in the calcium released.

\section{DISCUSSION}

The solubility of $\mathrm{HA}\left[\mathrm{Ca}_{10}\left(\mathrm{PO}_{4}\right)_{6}(\mathrm{OH})_{2}\right]$ is characterized by its solubility product. According to Dawes (2), when HA is in contact with water, the following reaction occurs:

$$
\begin{aligned}
\text { Precipitation } & \leftrightarrow \text { Demineralization } \\
\mathrm{Ca}_{10}\left(\mathrm{PO}_{4}\right)_{6}(\mathrm{OH})_{2} & \leftrightarrow 10 \mathrm{Ca}^{2+}+6 \mathrm{PO}_{4}^{3-}+2 \mathrm{OH}^{-} \\
\text {Solid } & \leftrightarrow \text { Solution }
\end{aligned}
$$

With reference to the above equation, on acidification the $\mathrm{OH}^{-}$will be removed by $\left[\mathrm{H}^{+}\right]$to form $\mathrm{H}_{2} \mathrm{O}$ and the $\mathrm{PO}_{4}{ }^{3-}$ will be removed to form $\mathrm{HPO}_{4}{ }^{2-}$, which on further acidification will form $\mathrm{H}_{2} \mathrm{PO}_{4}^{-}$. This will lead to a decrease in the $\left[\mathrm{OH}^{-}\right]$and $\left[\mathrm{PO}_{4}{ }^{3-}\right]$ on the right side of the equation. As the concentrations reach equilibrium, the solid will go into solution. The $\left[\mathrm{Ca}^{2+}\right]$ is however, not affected. That is why in an acidified solution, the Ip $<K s p$ (2). This condition was clearly reflected by the high dissolution rates due to the acidic beverages; Coke $^{\mathrm{TM}}$, Ribena ${ }^{\mathrm{TM}}$ and Sprite ${ }^{\mathrm{TM}}$ (Table 1, Figure 1). Coke $^{\mathrm{TM}}$ and Ribena ${ }^{\mathrm{TM}}$ did not show any significant

Table 1. The $\mathrm{pH}$ of the beverages recorded using a $\mathrm{pH}$ meter

\begin{tabular}{lc}
\hline BEVERAGES & $\mathrm{pH}$ \\
\hline Coke $^{\mathrm{TM}}$ & $2.43 \pm 0.00$ \\
Sprite $^{\mathrm{TM}}$ & $3.31 \pm 0.00$ \\
Ribena $^{\mathrm{TM}}$ & $3.02 \pm 0.00$ \\
Chrysanthemum tea $^{\text {Mineral water }}$ & $5.79 \pm 0.00$ \\
\hline
\end{tabular}




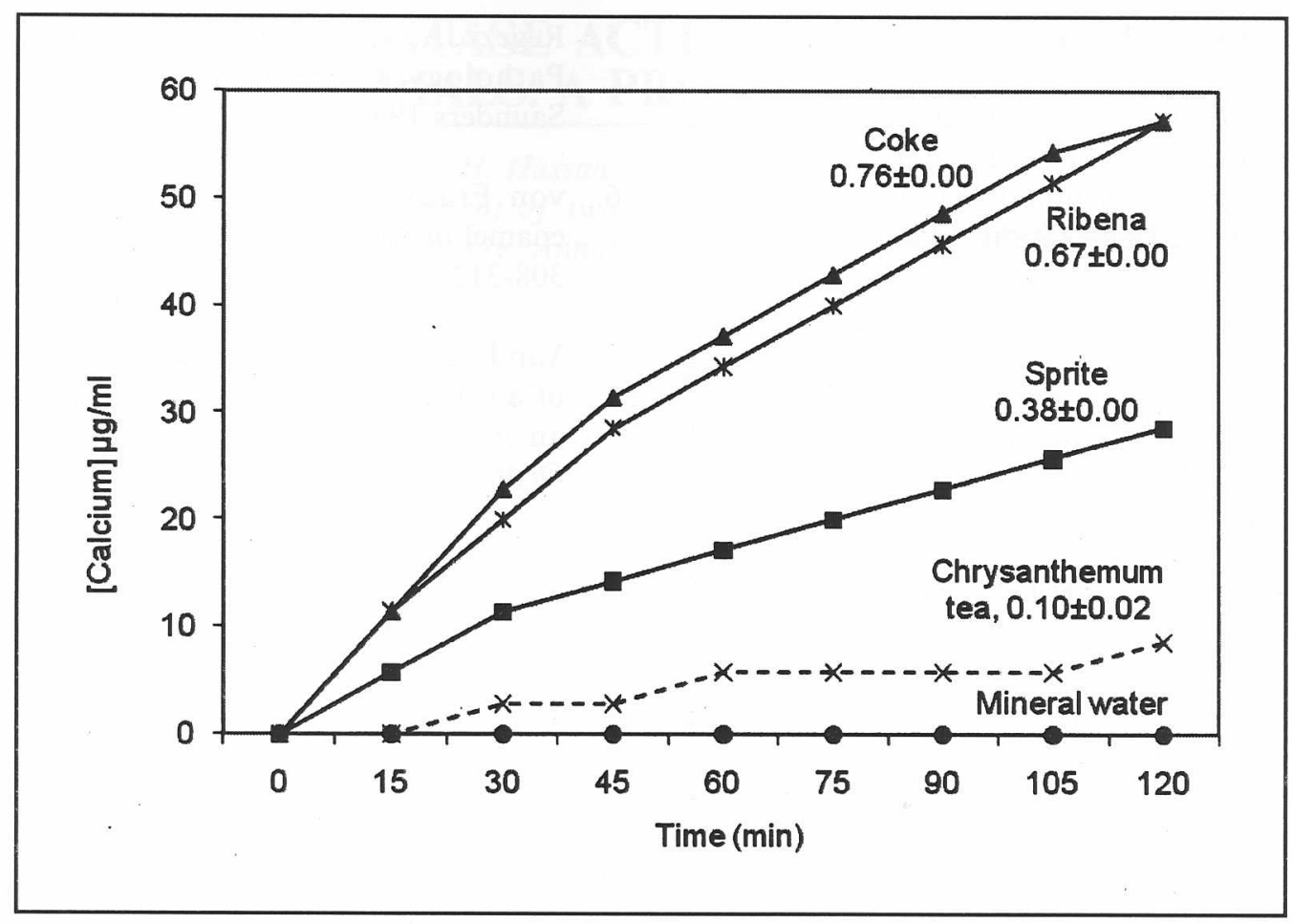

Figure 1: The profiles of calcium released from the enamel surface when exposed to the five types of beverages over a period of $120 \mathrm{~min}$. The rate of calcium released was determined by the amount of calcium released within the first $30 \mathrm{~min}$ of the experiment. The plotted values and the rate of calcium released were means \pm standard deviation from three determinations.

mean difference in their demineralising activity on the enamel surface $(\mathrm{p}<0.05)$ although Ribena ${ }^{\mathrm{TM}}$ has a $\mathrm{pH}$ value much higher than Coke ${ }^{\mathrm{TM}}$. Within the mouth however, the susceptibility of enamel dissolution is very much under the influence of factors such as $\mathrm{pH}$, salivary flow and buffering capacity of the oral fluid. The I $p$ generated following the consumption of acidic beverages would be regulated by the buffering components of the saliva (6). It has been reported that in an in vitro study carried out under a condition that simulated the drinking habit, that when enamel blocks were exposed to soft drinks at regular cycles of $20 \mathrm{~min}$ over a period of seven days, there was deterioration of the enamel microhardness. The frequency of the intake nevertheless, does not play a decisive role in causing the effect (7). Teeth in the oral cavity however, are very seldom under prolonged exposure to acid especially if the structure of plaque is thin, opened and porous. Based on such assumption, the rate of calcium released from the enamel surface on exposure to the five types of beverages in this study was focused and analyzed for the first $30 \mathrm{~min}$ of exposure. The extension of time to 2 hours exposure was carried out to provide an indication as to the pattern of calcium released when prolonged exposure to the beverages prevails.

In situ study has shown that the $\mathrm{pH}$ of plaque formed in association with acidic beverages did not always attain the critical $\mathrm{pH}$ (8). This may have been attributed to the buffering activity of the saliva. In the absence of saliva, the effect of acidic beverages would be detrimental on the enamel surface. Significant etching effect on the enamel surface occurs on prolonged exposure of enamel surface to very low $\mathrm{pH}$ (9). Lesions caused by the acid erosion have been reported to have a zone of softened enamel that is a few microns deep and is highly susceptible to physical wear (6). In this study, the demineralising effect of Coke ${ }^{\mathrm{TM}}$ and Ribena ${ }^{\mathrm{TM}}$ was shown to be the strongest among the acidic beverages. Chrysanthemum tea with the $\mathrm{pH}$ of 5.79 lies above the critical $\mathrm{pH}$ range and within the ideal $\mathrm{pH}$ of the saliva (5.5-6.5) (6), did not show any significant mean difference with mineral water in terms of their demineralising effect on the enamel surface.

\section{CONCLUSION}

The rate and amount of calcium released from the enamel surface was greatly influence by the $\mathrm{pH}$ of the beverages. The rate and amount of calcium released from the enamel were shown to be inversely dependent on $\mathrm{pHs}$ of the beverages. The lower the $\mathrm{pH}$ value, the higher was the rate and amount of calcium released from the enamel surface. 


\section{ACKNOWLEDGEMENT}

I would like to acknowledge Mohammad Faisal Md Yusoff and Raja Norhanizah Raja Hassan for their assistance in the completion of the study. The study was funded by the IRPA Grant, Malaysia.

\section{REFERENCES}

1. Avery JK. Oral Development and Histology. 2nd rev. ed. New York: Thieme 1994.

2. Dawes C. What is critical $\mathrm{pH}$ and why does a tooth dissolve in acid? J Can Dent Assoc. 2003; 69: $722-724$.

3. Pearce EI. Relationship between demineralization events in dental enamel and the $\mathrm{pH}$ and mineral content of plaque. Proc Finn Dent Soc 1991; 87(4): 527-539.

4. Cole AS, Eastoe JE. Biochemistry and Oral Biology. 2nd rev. ed. London: Butterworth International Edition 1988.
5. Regezi JA, Scuibba J. Oral Pathology. ClinicalPathology Correlations. 2nd rev. ed. WB Saunders 1993.

6. von Fraunhofer JA. Dissolution of dental enamel in soft drinks. Gen Dent 2004; Jul-Aug: 308-312.

7. Van Eygen I, Vannet BV, Wehrbein H. Influence of a soft drink with low $\mathrm{pH}$ on enamel surfaces: an in vitro study. Am J Orthod Dentofacial Orthop 2005; 128(3): 372-377.

8. Roos EH, Donly KJ. In vivo dental plaque $\mathrm{pH}$ variation with regular and diet soft drinks. Pediatr Dent 2002; 24(4): 350-353.

9. Featherstone JD, Lussi A. Understanding the chemistry of dental erosion. Monogr Oral Sci 2006; 20: 66-76. 